\title{
Virulence region of plasmid pNL2001 of Salmonella enteritidis
}

\author{
Shoko Suzuki, ${ }^{1}$ Katsuhiro Komase, ${ }^{2}$ Hidenori Matsui, ${ }^{2}$ Akio Abe, ${ }^{2}$ \\ Kazuyoshi Kawahara, ${ }^{2}$ Yutaka Tamura, ${ }^{1}$ Mayumi Kijima, ${ }^{1}$ Hirofumi \\ Danbara, ${ }^{3}$ Masayuki Nakamura' and Shizuo Sato ${ }^{4}$
}

Author for correspondence: Shoko Suzuki. Tel: +81042321 1841. Fax: +810423211769.

1 National Veterinary Assay Laboratory, 1-15-1 Tokura, Kokubunji-shi, Tokyo 185, Japan

2 The Kitasato Institute, 59-1 Shirokane, Minato-ku, Tokyo 108, Japan

3 Kitasato University, 5-9-1 Shirokane, Minato-ku, Tokyo 108, Japan

4 Zen-noh Institute of Animal Health, 7 Ohja, Sakura-shi, Chiba 285, Japan

\begin{abstract}
The virulence region of the Salmonella enteritidis 55 kb plasmid pNL2001 was identified by Tn1-insertion mutagenesis, DNA hybridization studies, and Western blot analysis of proteins encoded in the virulence region of the plasmid. DNA hybridization studies showed that the pNL2001 plasmid contained a $6.4 \mathrm{~kb}$ Sall-EcoRI fragment homologous to the $6.4 \mathrm{~kb}$ Sall-EcoRI Salmonella plasmid virulence (spv) region of the S. choleraesuis $50 \mathrm{~kb}$ plasmid (pKDSC50). One of the $247 \mathrm{Tn} 1$-insertion mutants of S. enteritidis, designated strain TA19, showed a reduced mouse lethality, and the Tn1-insertion of strain TA19 was located within this homologous $6.4 \mathrm{~kb}$ region, suggesting that the $6.4 \mathrm{~kb}$ Sall-EcoRI fragment of pNL2001 contained the spv region. Two contiguous Sall-EcoRI (2.3 kb) and EcoRI-EcoRI (4.1 kb) fragments derived from the $6.4 \mathrm{~kb}$ Sall-EcoRI fragment were cloned into the expression vectors. By Western blot analysis using four Spv peptide antisera, each specific for individual proteins encoded in the SpvR, spvA, spvB and spvC genes of pKDSC50, four proteins encoded in the 6.4 kb Sall-EcoRI fragment of pNL2001 were identified. Protein SpvR with an apparent molecular mass of 32 kDa was produced from the $2.3 \mathrm{~kb}$ Sall-EcoRI fragment, and proteins SpvA, SpvB and SpvC with apparent molecular masses of 32,70 and $29 \mathrm{kDa}$, respectively, were produced from the $4.1 \mathrm{~kb}$ EcoRI-ECoRI fragment. From the $4.1 \mathrm{~kb}$ EcoRI::Tn1 fragment of the TA19 plasmid, proteins SpvA and SpvB were expressed, but not SpvC. It was therefore suggested that the SpvC gene may contribute to the expression of virulence of $S$. enteritidis. Furthermore, the nucleotide sequence of the $6.4 \mathrm{~kb}$ Sall-EcoRI fragment encoding these four proteins was determined. Four open reading frames which encoded the four proteins with deduced molecular masses of 33906, 28200,65349 and 27646 Da were detected. Deduced amino acid sequences of each protein showed a high degree of identity to corresponding sequences in the virulence region of $S$. choleraesuis, S. dublin and S. typhimurium virulence plasmids. Therefore, we confirmed that the virulence plasmids of Salmonellae including $S$. enteritidis share the highly conserved region responsible for virulence.
\end{abstract}

Keywords: Salmonella enteritidis, virulence plasmid pNL2001, spv ABC genes

\section{INTRODUCTION}

Salmonella enterica subsp. enteritidis causes enteric and systemic infection in man and animals. $S$. enteritidis contains the serotype-specific large plasmid which is

The DDBJ accession numbers for the sequences reported in this paper are D14490 and D14491. responsible for virulence in mice (Nakamura et al., 1985; Hovi et al., 1988; Suzuki et al., 1989), as well as other nontyphoidal Salmonellae (Gulig, 1990). These virulenceassociated plasmids primarily contribute to the systemic infection of organisms beyond the intestine to the mesenteric lymph nodes, spleen and liver in mice (Gulig \& Curtiss, 1987; Heffernan et al., 1987; Suzuki et al., 1992). The identification of the virulence region of the plasmids is important to analyse the effect of the plasmid 
on mouse virulence. The virulence regions of the $S$. typhimurium, S. dublin and S. choleraesuis plasmids have been defined by deletion analysis, transposon mutagenesis or gene cloning (Baird et al., 1985; Michiels et al., 1987; Williamson et al., 1988b; Gulig, 1990; Kawahara et al., 1990). DNA sequence analysis of these virulence regions indicates that approximately $8.0 \mathrm{~kb}$ virulence regions of the $S$. typhimurium, $S$. dublin and $S$. choleraesuis plasmids are almost identical to each other, and encode at least five genes, spv R $A B C D$, which express proteins of 25-66 kDa (Norel et al., 1989a, b, c; Pullinger et al., 1989; Taira \& Rhen, 1989a, b, 1990; Gulig \& Chiodo, 1990; Matsui et al., 1990a b, 1993; Krause et al., 1991; Caldwell \& Gulig, 1991; Gulig et al., 1992, 1993).

Based on DNA hybridization studies and introduction of virulence plasmids into the different serotypes of $\mathrm{Sal}$ monella, it was predicted that the virulence plasmids of $S$. typhimurium, S. dublin, S. choleraesuis and S. enteritidis shared the homologous region associated with the virulence (Popoff et al., 1984; Beninger et al., 1988; Williamson $e t$ al., 1988a; Korpela et al., 1989; Poppe et al., 1989; Woodward et al., 1989; Roudier et al., 1990; Jones \& Osborne, 1991). Based on the results of electron microscopic heteroduplex analysis of the virulence plasmids from different serotypes, Montenegro et al. (1991) have reported recently that $S$. typhimurium, $S$. dublin, S. choleraesuis and $S$. enteritidis plasmids share large regions of homology. Although Williamson et al. (1988a) transduced a transposon insertion from the virulence region of the $S$. typhimurium and $S$. dublin plasmid to the $S$. enteritidis plasmid and showed that the resulting strains were avirulent in mice, the precise location of the virulence region of the $S$. enteritidis plasmid has not been identified. As a result, the genetic characterization of the virulence region of the $S$. enteritidis plasmid is poorly documented.

In this report, we describe the physical and genetic characterization of the $S$. enteritidis virulence plasmid pNL2001. We constructed a restriction endonuclease cleavage map of pNL2001 and found a $6.4 \mathrm{~kb}$ region encoding the virulence phenotype. Sequence analysis of this region revealed four sequential open reading frames encoding putative proteins of $29-70 \mathrm{kDa}$.

\section{METHODS}

Bacterial strains, plasmids, bacteriophages and media. $S$. enteritidis AL1190 contained the $55 \mathrm{~kb}$ (36 MDa) virulence plasmid pNL2001, and AL1192 was a plasmid-cured derivative of AL1190 (Nakamura et al., 1985). S. choleraesuis RF-1 (Kawahara et al., 1988), which contained the $50 \mathrm{~kb}$ virulence plasmid pKDSC50, was used for DNA hybridization studies and preparation of DNA probes. Eschericbia coli TH471 (Harayama et al., 1980) was used for transposon mutagenesis of pNL2001 as the transposon Tn1 carrier. E. coli HB101 (Bolivar \& Backman, 1979) and JM109 (Yanisch-Perron et al., 1985) were used as host strains for recombinant plasmids. pACYC184 (Chang \& Cohen, 1978), pUC118 and pUC119 (Viera \& Messing, 1987), and pHSG398 and pHSG399 (Takeshita et al., 1987) were used as cloning vectors. The nucleotide sequencing vectors were M13mp18 (Yanisch-Perron et al., 1985) and Bluescript M13 (Short et al., 1988). pMKD201 and pMKD401 carried the $4 \cdot 1 \mathrm{~kb}$ EcoRI-EcoRI fragment $(s p v A, s p v B$ and $s p v C$ genes) of pKDSC50 into pUC118 and the $2 \cdot 3 \mathrm{~kb}$ Sall-EcoRI fragment (spoR gene) of pKDSC50 into pUC119, respectively (Matsui et al., 1991). The growth media used were Antibiotic Medium 3 (Difco), Heart Infusion broth (Eiken), L broth (Lennox, 1955), L agar containing $1.5 \%(\mathrm{w} / \mathrm{v})$ agar, and desoxycholate-hydrogen sulfide-lactose agar (DHL; Eiken). Antibiotics were added for selection at the following concentrations: ampicillin (Ap), $25 \mu \mathrm{g} \mathrm{m}^{-1}$; kanamycin ( $\mathrm{Km}$ ), $25 \mu \mathrm{g} \mathrm{m}^{-1}$; chloramphenicol (Cp), $25 \mu \mathrm{g} \mathrm{ml}^{-1}$, and tetracycline (Tc), $12 \cdot 5 \mu \mathrm{g} \mathrm{ml}^{-1}$.

Preparation of restriction map. After timed partial digestion of the $55 \mathrm{~kb}$ plasmid pNL2001 with the restriction enzymes Sall, EcoRI or HindIII, digested fragments were cloned into pACYC184 and resulting recombinant plasmids were transferred to E. coli HB101 by transformation. The recombinant plasmid DNAs were isolated, digested, and analysed by $0.7-1.0 \%(\mathrm{w} / \mathrm{v})$ agarose gel electrophoresis.

Transposon mutagenesis of pNL2001 with Tn1. Insertion mutagenesis using $\operatorname{Tn} 1$ was performed as described previously (Nakamura et al., 1985), employing pTH10 as the transposon carrier. S. enteritidis AL1190 was mated with the donor strain E. coli TH471, which carries the pTH10 plasmid. $\mathrm{Ap}^{\mathrm{r}}$ and $\mathrm{Km}^{\mathrm{r}}$ Salmonella exconjugants were selected in glucose minimal medium containing Ap and $\mathrm{Km}$, and then cultured at $42{ }^{\circ} \mathrm{C}$ to select for the transposition of Tn 1 and the curing of pTH10. Resulting $A \mathrm{p}^{r}$ and $\mathrm{Km}^{\mathrm{s}}$ colonies were selected by replica plating, and plasmid DNA from these colonies was transferred into the plasmid-cured derivative AL1192 by the procedure of Kushner (1978) to exclude strains in which Tn1 had been inserted into the chromosome. These transformants were designated $\operatorname{Tn} 1$ inserts.

Mouse infection. Female ddY mice, 5 weeks old, were purchased from Nippon SLC. To screen for the strains carrying the plasmid in which $\operatorname{Tn} 1$ had been inserted into the virulence region, approximately $10^{5}$ c.f.u. of cultures $(0.1 \mathrm{ml})$ of $\mathrm{Tn} 1$ inserts were subcutaneously injected into the abdomen of three mice. Seven days after inoculation, $0 \cdot 1 \mathrm{ml}$ blood was collected by puncture of the retro-orbital venous plexus, inoculated in $3 \mathrm{ml}$ of Heart Infusion broth, and incubated at $37^{\circ} \mathrm{C}$ overnight. The overnight cultures were subcultured on DHL agar containing Ap at $37^{\circ} \mathrm{C}$ overnight. Mice were monitored for $14 \mathrm{~d}$ and deaths were recorded. The strain which was not recovered from the blood of mice and did not cause the death of inoculated mice was considered to be avirulent, as well as plasmid-cured strain AL1192. The others were considered to be virulent, as well as wild-type strain AL1190.

To determine the $\mathrm{LD}_{50}$ value of each strain, groups of five mice were inoculated with 10 -fold serial dilutions of cultures subcutaneously into the abdomen or intraperitoneally, and deaths were recorded over $14 \mathrm{~d}$. $L D_{50}$ values were calculated by the method of Behrens-Kärber (Kärber, 1931).

Genetic methods. Isolation of plasmid DNAs from Salmonella strains and from E. coli was performed by the method of Kado \& Liu (1981), and by the method of Holmes \& Quigley (1981), respectively. Purification of plasmid DNA was carried out by caesium chloride-ethidium bromide gradient ultracentrifugation. Transformation of plasmid DNA was performed as described by Kushner (1978) and Cohen et al. (1972). Restriction enzyme digestion, ligation and other molecular genetic manipulations were performed with enzymes purchased from Takara Shuzo or Toyobo, and were used according to the instructions supplied by the manufacturers. Digested DNA was electrophoresed at $100 \mathrm{~V}$ on $0.7-1.0 \%(\mathrm{w} / \mathrm{v})$ agarose gel prepared in TBE buffer $(40 \mathrm{mM}$ Tris base, $20 \mathrm{mM}$ sodium borate, 1 mM EDTA, pH 8.2). 
(a)

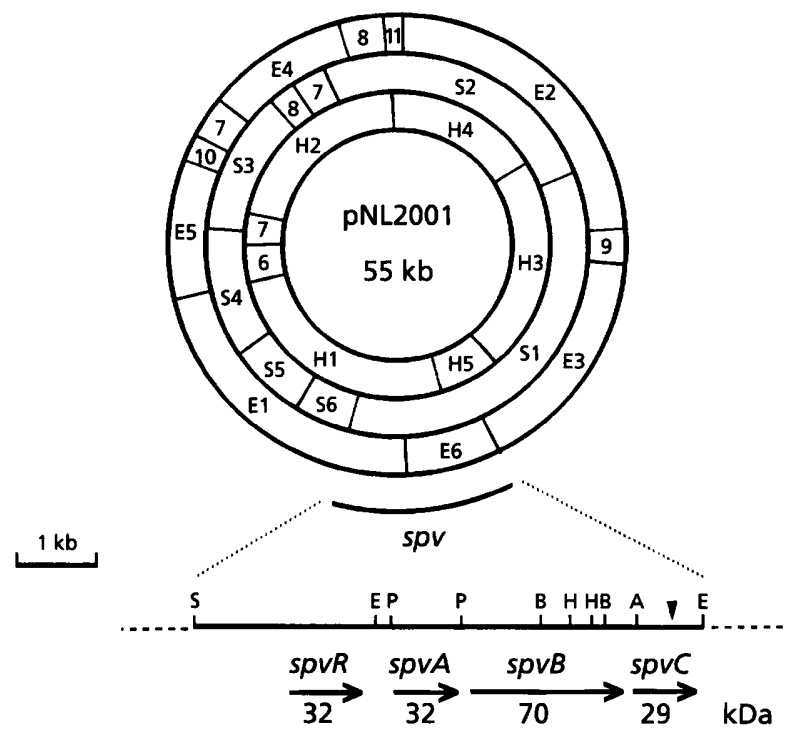

(b)

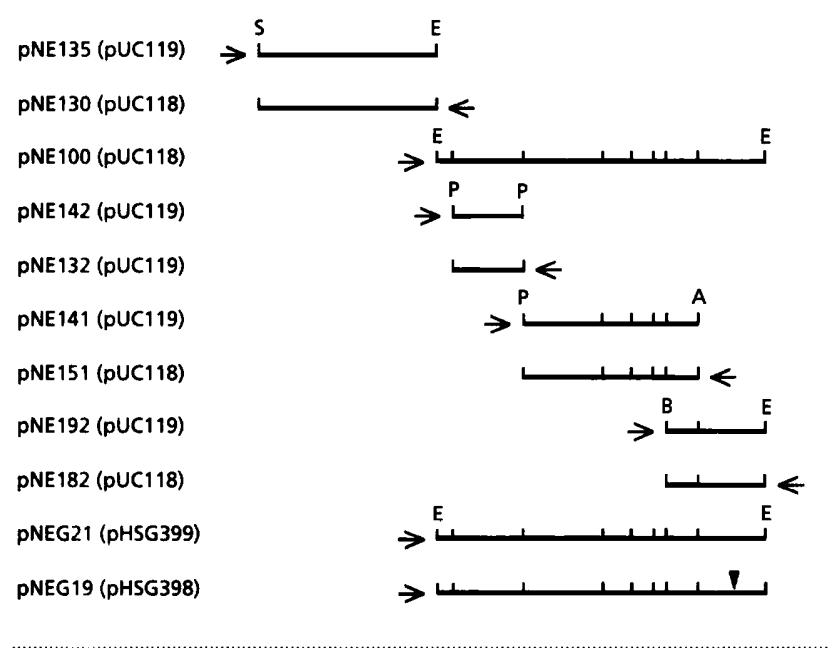

Fig. 1. (a) Restriction endonuclease map of the virulence plasmid pNL2001 of S. enteritidis. Spv represents the region associated with virulence in mouse. (b) Construction of the recombinant plasmids. Horizontal arrows and arrowhead indicate the lacZ promoter of the cloning vectors and Tn1 insertion site of strain TA19, respectively. Restriction endonuclease sites are as follows: A, Aatl; B, BamHI; E, EcoRI; $\mathrm{H}$, HindIII; P, Pstl; S, Sall.

Southern blot analysis. Plasmid DNAs pNL2001 and pKDSC50 were digested with Sall, HindIII and EcoRI, individually, or EcoRI and Sall together. Digested plasmid DNAs were fractionated on $1 \%(\mathrm{w} / \mathrm{v})$ agarose gel, and transferred onto a nylon membrane (Hybond-N+; Amersham). The probes from the $2.3 \mathrm{~kb}$ SalI-EcoRI fragment and $4.1 \mathrm{~kb}$ EcoRI-EcoRI fragment of pKDSC50 were labelled with horseradish peroxidase. Hybridization on nylon membrane and detection of chemiluminescent signals on X-ray film (HyperfilmECL, Amersham) were performed using ECL direct nucleic acid labelling and detection systems (Amersham) according to the manufacturer's instructions.
Table 1. Mouse lethality of an avirulent mutant of $S$. enteritidis

Mice were inoculated subcutaneously (SC) or intraperitoneally (IP).

\begin{tabular}{|llll|}
\hline Strain & \multicolumn{1}{c|}{ Plasmid } & \multicolumn{2}{c|}{$\begin{array}{l}\log \text { LD }_{\mathbf{5 0}} \\
\text { (c.f.u.) }\end{array}$} \\
\cline { 3 - 4 } & & SC & IP \\
\hline TA19 & pNL2001:: Tn1 & $7 \cdot 7$ & $5 \cdot 1$ \\
AL1192 & - & $8 \cdot 1$ & $6 \cdot 1$ \\
AL1190 & pNL2001 & $5 \cdot 6$ & $<2 \cdot 4$ \\
\hline
\end{tabular}

Antisera against individual Spv proteins. Antisera for Western blot analysis were prepared as described previously (Matsui et al., 1993). Briefly, oligopeptides were synthesized based on the amino acid sequence of hydrophilic regions near the C-termini of the SpvR, SpvA, SpvB and SpvC proteins encoded in the $s p v$

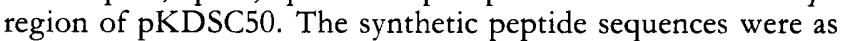
follows: SpvR, YPTKKRETPDYRKAIKLIQC; SpvA, SNYAMELASRLSPEQQTLPTEPDNS; SpvB, SKLRLSDDATADTNRIKRIC; SpvC, YRNELRSGRDGGEMQRQALREEPFYPLMTE. Individual antisera against $\mathrm{Spv}$ proteins were generated by immunization of rabbits with synthetic peptide-bovine serum albumin conjugates of corresponding proteins in Freund's complete adjuvant. Each serum exhibited a monospecificity based on examinations by ELISA (Matsui et al., 1993) and Western blot analysis using the system described below (data not shown), although some cross-reactivity was reported between the SpvR and $\mathrm{SpvB}$ proteins using these antisera (Matsui et al., 1993).

Western blot analysis. E. coli JM109 carrying the recombinant plasmid was cultured overnight in the presence of IPTG at a final concentration of $1 \mathrm{mM}$. SDS-PAGE was performed according to the method of Laemmli (1970). The proteins separated by SDS-PAGE were transferred electrophoretically to nitrocellulose paper (Bio-Rad). Non-specific antibody binding was blocked by incubating the nitrocellulose in $3 \%(\mathrm{w} / \mathrm{v})$ gelatin and $5 \%(\mathrm{v} / \mathrm{v})$ horse serum in TBS buffer $[20 \mathrm{mM}$ Tris (pH 7.5), $500 \mathrm{mM} \mathrm{NaCl}, 0.01 \%$ (w/v) merthiolate]. The blots were probed with rabbit antiserum against the Spv protein. Binding of the primary antibody was detected by using goat anti-rabbit immunoglobulin $G$ conjugated to horse radish peroxidase (HRP; Cappel) and then by incubating the preparation in HRP colour development reagent (containing 4chloro-naphthol) (Bio-Rad). E. coli JM109 carrying pMKD401 or pMKD201 were used as positive controls expressing the SpvR protein $(32 \mathrm{kDa})$ and SpvA $(32 \mathrm{kDa}), \mathrm{SpvB}(70 \mathrm{kDa})$ and SpvC (29 kDa) proteins, respectively. E. coli JM109 carrying the vector plasmid was used as a negative control.

Nucleotide sequencing. The $2.3 \mathrm{~kb} S a l \mathrm{I}-E c o \mathrm{RI}$ and $4.1 \mathrm{~kb}$ EcoRI-EcoRI fragments of pNL2001 were cloned into Bluescript M13 and M13mp18, respectively. Nucleotide sequencing was performed with an automatic 373A DNA sequencer using the Taq Dye Deoxy Terminator Cycle Sequencing kit (Applied Biosystem). Sequencing primers were provided in the kit. All the sequences were read from both strands. DNA sequences flanking $\operatorname{Tn} 1$ insertions were determined by using oligonucleotides corresponding to the termini of $\operatorname{Tn} 3$ (Heffron $e t$ al., $1979)$ as primers. The sequence data were analysed with DNA software, GENETYX-MAC (Software Development Co.). 
(a)

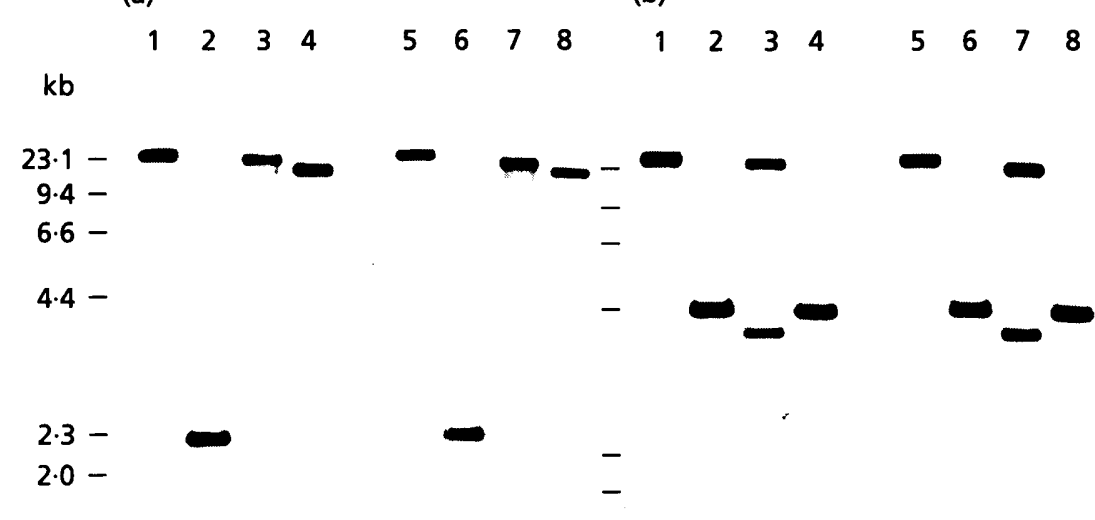

Fig. 2. Southern hybridization analysis of pNL2001 with $2.3 \mathrm{~kb}$ Sall-ECORI (a) and $4.1 \mathrm{~kb}$ EcoRl-EcoRI (b) probes derived from pKDSC50. pNL2001 (lanes 1-4) and pKDSC50 (lanes 5-8) were digested with Sall (lanes 1 and 5), Sall plus ECORI (lanes 2 and 6), Hindili (lanes 3 and 7) and EcoRI (lanes 4 and 8). HindIII fragments of $\lambda$ DNA were used as molecular mass standards. (a)

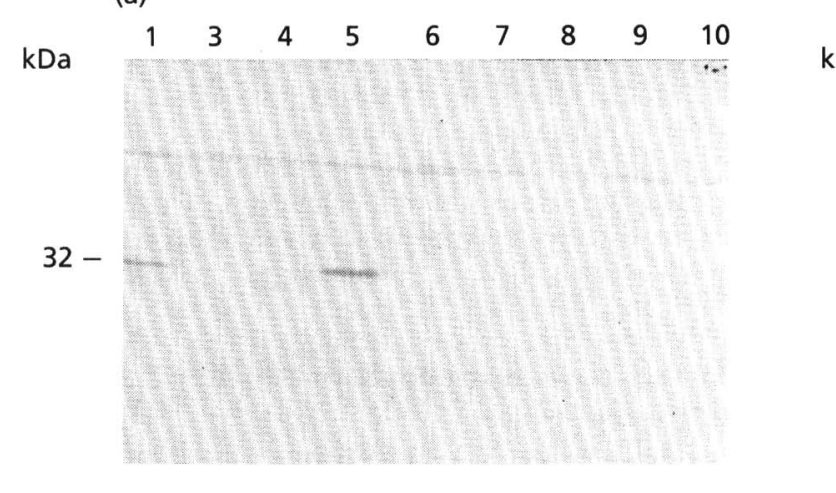

(c)

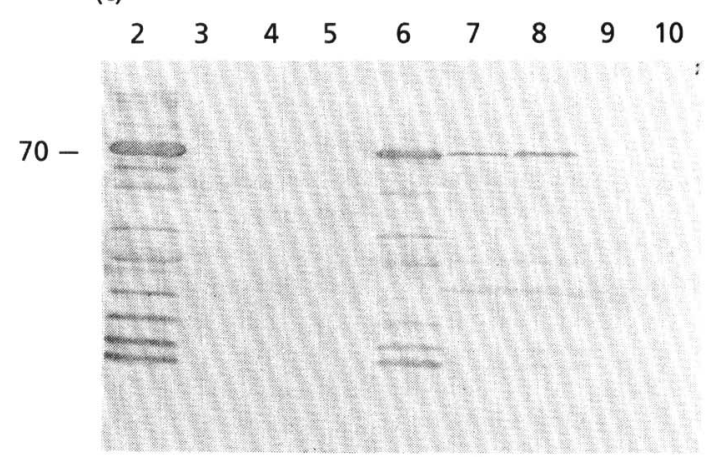

(b)

$\begin{array}{llllllllll}\mathrm{kDa} & 2 & 3 & 4 & 5 & 6 & 7 & 8 & 9 & 10\end{array}$

$32-$

(d)

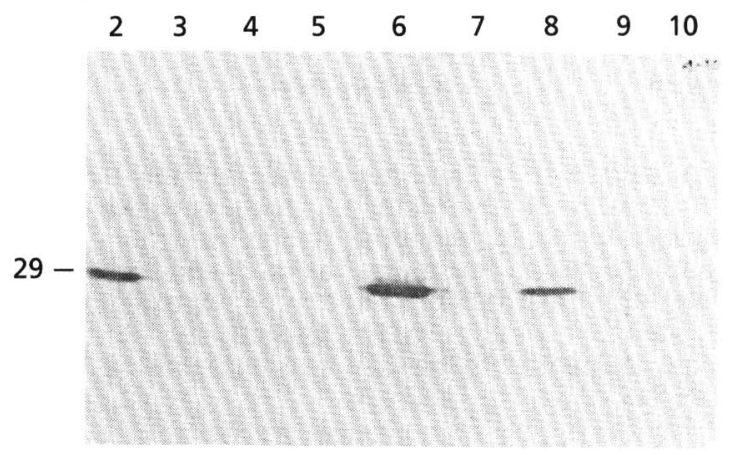

Fig. 3. Western blot analysis of Spv proteins expressed from recombinant plasmids. Lanes: 1, JM109/pMKD401; 2, JM109/pMKD201; 3, JM109/pUC118; 4, JM109/pUC119; 5, JM109/pNE135; 6, JM109/pNE100; 7, JM109/pNEG19; 8, JM109/pNEG21; 9, JM109/pHSG398; and 10, JM109/pHSG399. Spv peptide antisera used were as follows: anti-SpvR serum (a), anti-SpvA serum (b), anti-SpvB serum (c) and anti-SpvC serum (d).

\section{RESULTS}

\section{Endonuclease restriction map}

In the agarose gel electrophoretic patterns of pNL2001 digested with Sall, EcoRI and HindIII, there were 8 Sall sites, 11 EcoRI sites (the first and third bands of the EcoRI digest were doublets), and 7 HindIII sites (the second band of the HindIII digest was a doublet). With the timed partial digest of pNL2001 with each enzyme, the restriction map of pNL2001 was constructed as shown in Fig. 1. Compared with the restriction enzyme sites, the maps of pNL2001 and pKDSC50 (Kawahara et al., 1990) 
Sa/ I

1 GTCGACTTCATCCTGATAAAACACAGGATGTGCAGTCTGCTCCTGAGCCAGCGCCTGATCAATGACAAGCCGTTITTCTT CATAGTGCGGATCTTTGATTTTCAGCGTTGGCGCTGCCCTGCGCCAGACCATATCTGCCTGCCTCAGATATCGGTGCAGG GTGGAGCGGTGCAGCGTCACCAAAAAGTCGGTTGATGACGAGTACCAGAAGCTCCGTGCTCCAGCGTGAGCGCAGCATCA GCCAAAATCCTTCGGGGAACGCTGTACCAATAGTGGCAAGAGCTGAAGGATATCAGCGACCGGCCAGCGTGGAGCACGTC CGGGTCTGAGGCTITTTAGTCCTTCAACACCATGTAAAGTAAACCAGTTTATCCATCGACCAACGGATGAACGGGCGGCA CAGAGTAATCTGGCAACGTCAGTGACGGTCATTCCCTGATGCAGCATCAGCATGGCGATAAGCCGTCGCGCATGGTTIIT ATCGTAGGTTTGTTGGGCCTCTTTGCGCATCAGTTGTCGTTCTTCATCAGGAATTGCTGCTATGATCGGCATCGCTCAGT CCGGTTGGTGATTTGTGATGTTTGGCGATTGATCAGATCCCACAATCCGGGCTGAGTTCCCTTTCAGTGATCTACTATTT TGCGAAGCTATTTAGTGCACACTAATCGATTTTTCAGACAACCTTTCTCGCCTGGCGTGAGTTTTCGTTCGACTGAACCT АTAAAАAGCCTCTGCATTCTGTCCTGTAGTGCGCCAGGCCTAATAACGCCTCCCGTTTA МTTCCGGCCCGGTCGTACATC GGTTCTGTTCATTTATGGGATCGCGACTTITTCGTTGTAATGCTTCAAGAGCGATTIITTGTTCTGCGGTCAACTCAACA TTCATAGCCATCAGCATGATCCTGATTATTTTTGAAACCAAGCATCTTCATTGATCATGGGTATACATCGTTGTTATCCA GCTATACATCATAACAGGTCAATTAAATCCACTCAGAAATAAAGTCAGGGTATGCATAAAATCTATCGCCCATAATCCTA TCCAGTAACACCATGATTAGTAAGA ЙTAATCAGTCTGTGCAAAAACAGGTCACCGCCATCCTGTITITGCACATCAAAA

$$
\longrightarrow \text { SPVR }
$$

CATTITCAGGATTATTCTGAAAAAAA AGGAGATATTATGGATTTCTTGATTAATAAAAAATTAAAAATTTTCATAAC

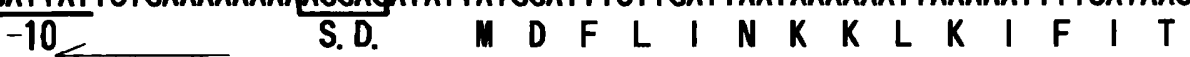
ACTGATGGĀACAGGTTCCTTCAGTATCGCAACATCAGTACTGTATATCACCCGAACCCCGCTGAGCAGGGTTATTTCAG L M E T G S ACCTGGAAAGAGAGCTGAAACAAAGACTCTTTATACGGAAGAATGGCACTCTTATCCCAACCGAATTTGCACAAACTATT

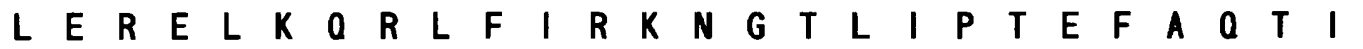
$\begin{array}{lllllllllllllllllllllllllll}Y & R & K & V & K & S & H & Y & \text { I } & F & L & H & A & L & E & O & E & \text { I } & G & P & T & G & K & T & K & O & L\end{array}$ AGAAATAATATTTGACGAAATTTATCCGGAAAGTTTAAAAAATCTGATCATTTCAGCACTGACCATTTCCGGCCAAAAAA

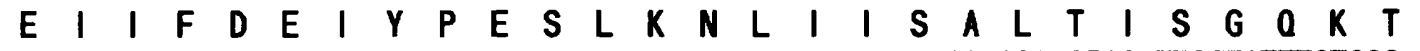
CAAATATAATGGGGAGAGCCGTTAACAGCCAAATAATAGAAGAACTGTGTCAGACAAACAACTGCATTGTTATTTCTGCC $R$ N Y F H R E S L V C R T S V E G G V M L F I P K K F

Fig. 4. Nucleotide sequence of the SpvR region. The DNA sequence of the $2 \cdot 3 \mathrm{~kb}$ Sall-EcoRI region of pNL2001 and deduced amino acid sequence of the coding region are indicated. The horizontal arrows and the asterisk indicate inverted repeats and the stop codon, respectively. Potential promoter $(-35$ and -10$)$ and Shine-Dalgarno (S.D.) sequences are also marked.

resembled each other, especially in the region encompassing the $s p v$ region.

\section{Tn1-insertion mutants}

To identify the S. enteritidis virulence region of pNL2001, transposon insertion mutagenesis with $\operatorname{Tn} 1$ was carried out, and 247 insertion mutants were obtained from $S$. enteritidis AL1190. In a screening for avirulent mutants, only one of them, designated strain TA19, induced neither bacteraemia nor death in mice. The $\mathrm{LD}_{50}$ of strain TA19 was almost the same as that of strain AL1192, whilst strain AL1190 showed a lower $\mathrm{LD}_{50}$ (Table 1). Based on restriction enzyme analysis of plasmid DNA from strain 
ECORI

1 GAATTCCTGAATGGGACCACGCCAGCGGTCAGGTTGTTCCCEGCCTGACCCGACECCGGAGCGCTGAACGTTGTTTATT

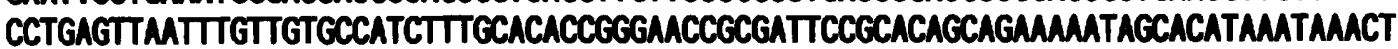
Pst 1

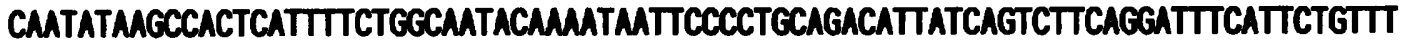
$\longrightarrow$ SPVA

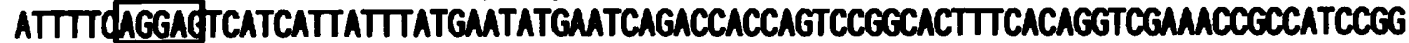
S. D. II N II N GTCCCCOCAGGGATTTTGCAAATATAМTATTATTCCGTGTTTGATATTGTCCGTCAGACCCGTAACAGTTTATTA $\begin{array}{lllllllllllllllllllllllllll}V & P & A & G & N & F & A & K & Y & N & Y & Y & S & V & F & D & I & V & R & O & T & R & K & O & F & I & N\end{array}$ CECCAATATGTCATEGCCGEGCTCCCGCGGAGGTAMECCTGEGACCTEECGATGGECCAGECECAGTATATCCECTECA

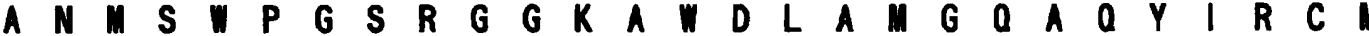

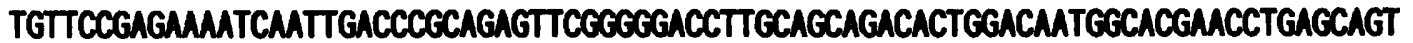

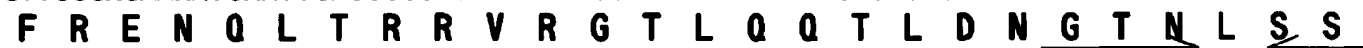
TCCECTGTCEGCGGTATTCAGGGACA GGCAGAGCGTCGECCGGACCTGECCACCCTGATGGTGGTTATGATGCCATTAA S A A V G G I

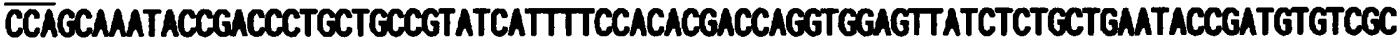
$\begin{array}{lllllllllllllllllllllllllll}0 & 0 & I & P & T & L & L & P & Y & H & F & P & H & D & 0 & V & E & L & S & L & L & N & T & D & V & S & L\end{array}$ TGGAGATATTATCAGCGAGAGCAGCATTGACT GECCGTGGTTCCTGACCAACTCCCTGACCGGCGATACAGTAACTAT

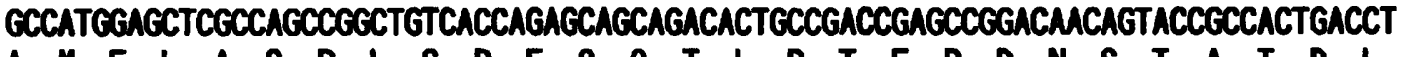

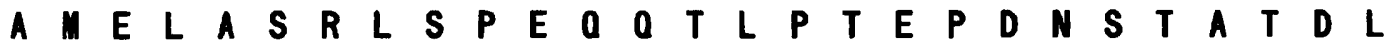
gACCTCTITITACCAGACCAATCTGGGGCTGAAAACCGCCGACTATACGCCATTTGAGCACTGATTACCTTTGCCCGAC

AGTTAGCGATTACCGTTCCCCCAGGTGGAACAGTTGATTGCGGGTACTCTCCGTGCCAGCCGECAGTTTAGCTTCCCGCG $\begin{array}{lllllllllllllllllllllll}L & A & I & T & V & P & P & G & G & T & V & D & C & G & Y & S & A & C & O & P & A & V & *\end{array}$ Pst I

1041 CTACCAGAGTAGTGAGCAGCAGACCATTCTGCAGATCTGAGCGACGTCATTGTTCAGGTGCATTCTACCOCGGTGTACG GCEGCAGCACTTTTGACAGECCGTAGAGCAGACECTGTAACCAGAAAATATACCTGECCATCGTCAGACGECCAGTTTC $\longrightarrow \operatorname{spn} B$

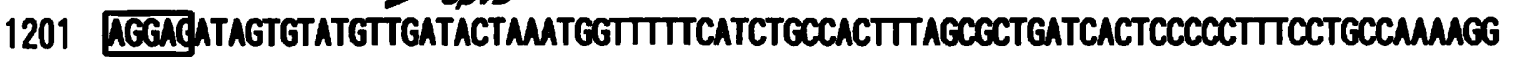
S.D.

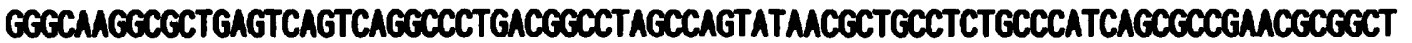
$\begin{array}{lllllllllllllllllllllllllll}G & K & A & L & S & 0 & S & G & P & D & G & L & A & S & I & T & L & P & L & P & I & S & A & E & R & G & F\end{array}$

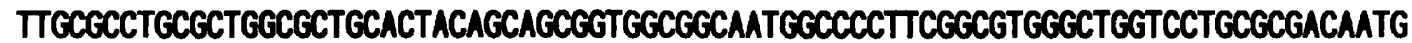
AGCATTGCCCECAGCACCAGCCATEECGTGCCGCAGTATMACGACAGCGATGAGTTTCTGGGGCCGGACGGAGAGTGCT $\begin{array}{lllllllllllllllllllllllllll}S & I & A & R & S & T & S & H & G & V & P & O & Y & N & D & S & D & E & F & L & G & P & D & G & E & V & L\end{array}$

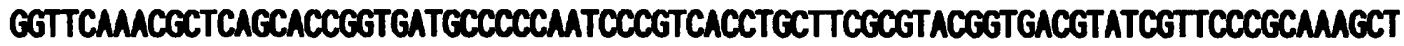
$\begin{array}{lllllllllllllllllllllllllll}V & A & T & L & S & T & G & D & A & P & N & P & V & T & C & F & A & Y & G & D & V & S & F & P & O & S & Y\end{array}$

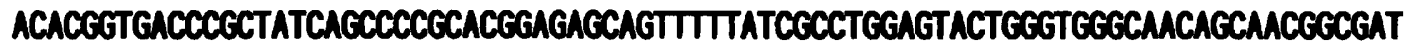

\section{$\begin{array}{llllllllllllllllllllllllll}T & V & T & R & Y & \text { Q } & P & R & T & E & S & S & F & Y & R & L & E & Y & V & G & N & S & N & G & D\end{array}$} GATTCTGGTTACTECATGACAGTAACGECATCCTGCACCTCCTEGGGUAACCECCECAGCACGCCTCA GCGATCCGCA D $F: L L E$ L GECСECCTCTCATACEGCGCAATGECTGGTTGAGGAGTCGGTGACCCCTCCCGGCGAGCATATCTATTACTCCTACCTGG CEGAGAACGGTGACAATGTGGACCTCAATGEgAACGAGECCGgACGCGATCECAGCGCCATECGCTATCTCAGCAAGGTA

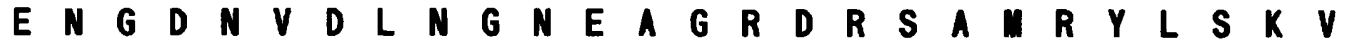
CAGTATGECAACGCGACCCCCECCECCGATCTGTACCTCTGGACTAGCCCCCACACCCECGGTACAGTGECTGTTCACCCT $\begin{array}{lllllllllllllllllllllllllll}\text { a } & Y & G & N & A & T & P & A & A & D & L & Y & L & T & T & S & A & T & P & A & V & Q & \| & L & F & T & L\end{array}$

264 AGTGTTTGACTACGGCGACGTGGTGTAGATCCACAGGTACCGCCTGCATTCACTGCTCAGACAGCTGECTCGCCCGCC $\begin{array}{llllllllllllllllllllllllllllllllll}V & F & D & Y & G & E & R & G & V & D & P & Q & V & P & P & A & F & T & A & 0 & N & S & I & L & A & R & 0\end{array}$ Bam HI

80

160

240

320

19

400

46

480

73

560

99

640

126

720

153

800

179

880

206

960

233

1040

255

1120

1200

1280

1360

50

1440

76

1520

103

1600

130

1680

156

1760

183

1840

210

1920

236

2000

263

2080

290

2160

2240

343 
2241

344

2321

371

2401

397

2481

424

2561

2641

477

2721

504

2801

531

2881

557

2961

584

3041

3121

3201

3441

59

3521

85

3601

112

3681

139

3761

165

3841

192

3921

219

4001

4081
GCTTTGCGCTGCTCGGACGCTGGCCTATGAAGGCGACGGTTATAGAAGAGCTCCTGTCAACAATATGATGCCACCGCCAC $\begin{array}{lllllllllllllllllllllllllll}L & C & A & A & R & T & L & A & Y & E & G & D & G & Y & R & R & A & P & V & N & N & M & M & P & P & P & P\end{array}$ CGCCTCCTCCGATGATGGGAGGTAATTCATCTCGACCAAAATCAAAATGGGCGATTGTAGAGGAATCAAAGCAGATTCAA $\begin{array}{lllllllllllllllllllllllll}P & P & P & M & G & G & S & S & R & P & K & S & K & A & I & V & E & E & S & K & 0 & I & a\end{array}$ GCTCTGAGGTACTATTCAGCTCAAGGGTACAGTGTGATTAATAAATATTTACGTGGGGATGATTATCCTGAAACACAGGC $\begin{array}{lllllllllllllllllllllllllll}A & L & R & Y & Y & S & A & O & G & Y & S & V & I & N & K & Y & L & R & G & D & D & Y & P & E & T & O & A\end{array}$ AAAAGAAACTCTGCTCTCCAGAGACTATCTTTCCACAAATGAACCCAGTGATGAGGAGTTTAAAAATGCCATGTCAGTTT $\begin{array}{lllllllllllllllllllllllllll}K & E & T & L & L & S & R & D & Y & L & S & T & N & E & P & S & D & E & E & F & K & N & A & M & S & V & Y\end{array}$ Hind III

ATATAAATGATATTGCGGAGgGATTAAGTTCACTTCCCGAAACAGATCACAGAGTCGTATACCGGGGCCTGAAGCTTGAT I N $N$ D I A Hind III

AAGCCCGCATTATCGGATGTGCTGAAGgAATACACTACTATAGgTAATATAATAATAGATAAAGCTTTTATGAGTACATC 2720 K $P$ P A L L S D V V L GCCAGATAAGGCATGGATAAATGACACTATTCTCAACATATACCTAGAAAAAGGACATAAAGGTAGAATACTCGgAGATG 2800 $\begin{array}{llllllllllllllllllllllllllll}\text { P } & D & K & A & \text { I } & \text { I } & \text { N } & \text { D } & T & \text { I } & \text { L } & \text { N } & \text { I } & \text { Y } & \text { L } & \text { E } & K & G & \text { H } & K & G & R & \text { I } & \text { L } & G & D & V & 530\end{array}$ Bam HI

TTGCACATTITAAGGGAGAGGCAGAGATGCTTTTCCCTCCAAATACTAAACTCAAAATCGAAAGCATTGTAAATTGTGGA

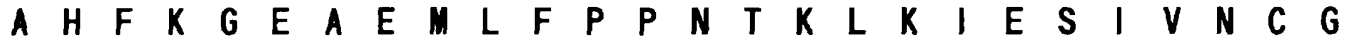
TCCCAAGACTTTGCAAGCCAGCTTAGTAAGCTGAGATTAAGTGATGATGCAACTGCTGACACAAACAGGATAAAAAGATT \begin{tabular}{llllllllllllllllllllllllllll}
$S$ & $Q$ & $D$ & $F$ & $A$ & $S$ & 0 & $L$ & $S$ & $K$ & $L$ & $R$ & $L$ & $S$ & $D$ & $D$ & $A$ & $T$ & $A$ & $D$ & $T$ & $N$ & $R$ & $I$ & $K$ & $R$ & $I$ \\
\hline
\end{tabular} AATAAACATGAGGGTACTCAACTCATAGATACTAAGAATCTATTCCAGAAGTGGTATGAGCGGCCTAGCTCTATAAGGGG I N R R L N S * ПTATACTCCGG TICCCCAGATIITTCCGTCACCCTAGGCCCGCAAAGTAGTGCATCTAAACTITTGCCATTACCCTTCTT TAACTTTCTCCTCGGAACGGACCGAAATATCATTITICGCCTGATAAAAATGAGGTTTTCTGGATAACTAATCGTTT $\longrightarrow$ spve ATTAAAаAаACTGAGAATTIATATCTAATAATATGGCGATATATCCKTATCGCA AGGAGATTTCCCATGCCCATAAAT

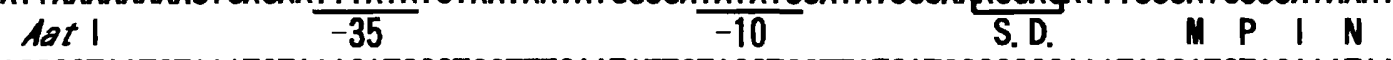
AGGCCTAATCTAAATCTAAACATCCCTCCTTTGAATATTGTAGCTGCTTATGATGGGGCGGAAATACCATCTACAAATAA $\begin{array}{lllllllllllllllllllllllllll}R & P & N & L & N & L & N & \text { I } & P & P & L & N & I & V & A & A & Y & D & G & A & E & I & P & S & T & N & K\end{array}$ GCACCTGAAAAATAATTTCAACTCCTTGCACAACCAAATGCGGAAGATGCCGGTATCCCACTTTAAAGAGGCGCTGGATG $\begin{array}{lllllllllllllllllllllllllll}H & L & K & N & N & F & N & S & L & H & N & 0 & M & R & K & M & P & V & S & H & F & K & E & A & L & D & V\end{array}$ TGCCTGACTATTCAGGGATGCGCCAGAGTGGTTTCTTTGCTATGAGCCAAGGTTITCAGCTGAATAACCATGGTTACGAT $\begin{array}{llllllllllllllllllllllllll}P & D & Y & S & G & M & R & 0 & S & G & F & F & A & M & S & O & G & F & O & L & N & N & H & G & Y & D\end{array}$ GTITTCATCCATGCTCGTCGAGAATCACCTCAGTCTCAGGCCAAATTTCCCGGTGACAAGTTCCACATCAGTGTGCTCAG $\begin{array}{lllllllllllllllllllllllllll}V & F & \text { I } & H & A & R & R & E & S & P & O & S & Q & G & K & F & A & G & D & K & F & H & I & S & V & L & R\end{array}$

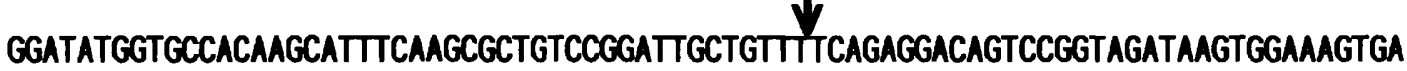
$\begin{array}{lllllllllllllllllllllllllll}D & \text { II } & V & P & \text { O } & A & F & \mathbf{C} & A & L & S & G & L & L & F & S & E & D & S & P & V & D & K & & K & V & T\end{array}$ CCGATATGGAGAGGTCGTTCAACAAGCCCGTGTTAGCCTGGGCGCTCAGTTCACGTTGTATATAAAACCAGACCAGGAA

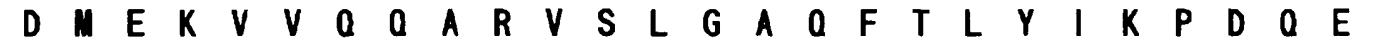
AATTCGCAGTACAGTGCGTCGTTTCTCCACAAGACACGGCAATTTATAGAGTGTCTGGAATCCAGACTATCCGAAAATGG $\begin{array}{lllllllllllllllllllllllllll}N & S & 0 & Y & S & A & S & F & L & H & K & T & R & 0 & F & \text { I } & E & C & L & E & S & R & L & S & E & N & G\end{array}$ GGTTATTTCAGGACAGTGTCCTGAGTCAGACGTTCATCCTGAAAATTGGAAATATCTCAGTTATCGTAATGAACTACGAA $\begin{array}{lllllllllllllllllllllllllll}V & I & S & G & O & C & P & E & S & D & V & H & P & E & N & W & K & Y & L & S & Y & R & N & E & L & R & S\end{array}$ GTGGGCGTGATGGTGGTGAAATGCAGAGACAGGCTTTACGTGAGGACCGTTITATCGTTTGATGACAGAGTAAGTATGG

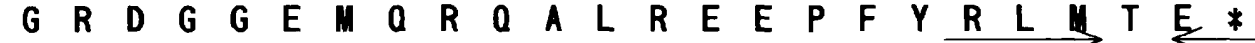

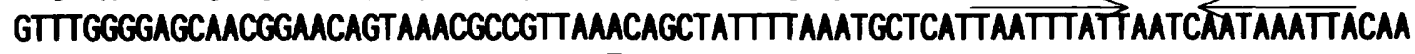
ECORI

ATTTTCATTGAAGGCTCCCCCCTTACTGACGAATTC

2880

556

2960

583

3040

591

3120

3200

3280

4

3360

31

3440

58

3520

84

3600

111

3680

138

3760

164

3840

191

3920

218

4000

241

4080

4116

Fig. 5. Nucleotide sequence of the spvA-spvC region. The DNA sequence of the $4 \cdot 1 \mathrm{~kb}$ EcoRI-EcoRI region of pNL2001 and deduced amino acid sequences of the coding regions are indicated. The horizontal arrows, asterisk, and arrowhead indicate inverted repeats, the stop codon, and Tn1 insertion site of strain TA19, respectively. Potential promoter (-35 and -10 ) and Shine-Dalgarno (S.D.) sequences are also marked. 
TA19, the Tn1-insertion site was detected in the $1.4 \mathrm{~kb}$ region of the HindIII-EcoRI fragment of the plasmid (indicated by the arrowhead in Fig. 1).

\section{Southern blot analysis}

To identify the homologous virulence region in pNL2001, the $2.3 \mathrm{~kb}$ SalI-EcoRI fragment of $S$. choleraesuis plasmid pKDSC50, containing the $s p v R$ gene, and the $4.1 \mathrm{~kb}$ EcoRI-EcoRI fragment, containing the $s p v A, s p v B$ and $s p v C$ genes, were used as probes for Southern blot analysis. As shown in Fig. 2(a) and (b), the $2.3 \mathrm{~kb}$ and $4.1 \mathrm{~kb}$ probes hybridized with the $2.3 \mathrm{~kb} S a l l-E c o R I$ and $4.1 \mathrm{~kb}$ EcoRI-EcoRI (EcoRI-6) fragments of the $55 \mathrm{~kb}$ plasmid pNL2001 of $S$. enteritidis, respectively. The $2.3 \mathrm{~kb}$ probe also hybridized with the SalI-1, EcoRI-1 and HindIII-1 fragments in the restriction enzyme map of pNL2001 (Fig. 1). Accordingly, it was demonstrated that the $2.3 \mathrm{~kb}$ Sall-EcoRI fragment was contiguous to the EcoRI-6 fragment, and that the $6.4 \mathrm{~kb} S a l-E c o R I$ fragment homologous to the $s p v$ region of pKDSC50 was present in pNL2001.

\section{Identification of proteins encoded by the virulence region}

To identify the proteins encoded in the $6.4 \mathrm{~kb} S a l I-E c o R I$ fragment of pNL2001, E. coli JM109 carrying the various recombinant plasmids (Fig. 1 b) were analysed by Western blotting using four antisera against individual SpvR, SpvA, SpvB and SpvC proteins expressed from the $6.4 \mathrm{~kb}$ $s p v$ region of the $S$. choleraesuis plasmid pKDSC50. The recombinant plasmids were constructed using pUC118, pUC119, pHSG398 or pHSG399 as cloning vectors. Results of Western blot analysis are shown in Fig. 3. AntiSpvR serum enabled detection of the $32 \mathrm{kDa}$ protein in JM109/pMKD401 used as a positive control for SpvR, but not in JM109/pMKD201 (data not shown). AntiSpvA, -SpvB and -SpvC sera enabled detection of the 32, 70 and $29 \mathrm{kDa}$ proteins in JM109/pMKD201, respectively, but not in JM109/pMKD401 (data not shown). None of the proteins were detected in the JM109 strains carrying the vector plasmid. One protein, designated SpvR with a molecular mass of $32 \mathrm{kDa}$, was detected in cells carrying pNE135 or pNE130, and three proteins of 70,32 and $29 \mathrm{kDa}$, were detected in cells carrying pNE100 or pNEG21. To confirm the order of the proteins expressed in the $4.1 \mathrm{~kb} E c o \mathrm{RI}-E_{c o \mathrm{RI}}$ fragment of pNL2001, 0.9 kb Pst $\mathrm{I}-$ Pst $\mathrm{I}, 2.2 \mathrm{~kb}$ Pst $\mathrm{I}-$ Aat $\mathrm{I}$ and $1.2 \mathrm{~kb}$ Bam HI-EcoRI fragments from the $4.1 \mathrm{~kb}$ EcoRI-EcoRI fragment were subcloned into the vector plasmids pUC119 or pUC118. pNE141 and pNE151 were constructed by insertion of the PstI-AatI fragment from pNE100 into the PstI-SmaI site of pUC119 and pUC118, respectively. The $70 \mathrm{kDa}$ protein was detected in JM109/pNE141, the $32 \mathrm{kDa}$ protein in JM109/pNE142, and the $29 \mathrm{kDa}$ protein in JM109/pNE192 and JM109/pNE182, indicating that the order of the molecular mass of the proteins designated SpvA, SpvB, and SpvC from left to right along the fragment was 32,70 and
$29 \mathrm{kDa}$, respectively (Fig. 1a). No proteins were detected in JM109/pNE132 or JM109/pNE151, indicating that the translational orientations of the SpvA and SpvB proteins were as shown in Fig. 1(a) along the $4.1 \mathrm{~kb}$ EcoRI-EcoRI fragment. SpvR and SpvC proteins were detected in JM109/pNE130 and JM109/pNE182, respectively, suggesting the presence of a promoter sequence in each fragment.

The EcoRI-6:: Tn1 fragment of the TA19 plasmid was cloned into the vector plasmid pHSG398, designated pNEG19, and proteins expressed from pNEG19 were examined. From pNEG19, SpvA and SpvB were expressed, unlike SpvC. No truncated protein was detected (Fig. 3, lane 7).

\section{Determination of DNA sequences of the region involved in S. enteritidis virulence}

The DNA sequence of the $6.4 \mathrm{~kb} S a / I-E c o$ RI fragment of pNL2001 was determined (Figs 4 and 5). Four open reading frames consisting of $891,765,1773$ and 723 bp were identified from nucleotides 1160-2050 at the Sall site of the $2.3 \mathrm{~kb} S a l \mathrm{I}-E c o$ RI fragment (Fig. 4), and from nucleotides 264-1028, 1213-2985 and 3269-3991 at the left EcoRI site of the $4 \cdot 1 \mathrm{~kb}$ EcoRI-EcoRI fragment (Fig. $5)$, respectively. These open reading frames encoded peptides with deduced molecular masses of 33906,28200 , 65349 and $27646 \mathrm{Da}$, which were in good agreement with the sizes estimated from Western blot analysis.

The consensus ribosome-binding sites (AGGAG) were identified in a region $6-13$ bp upstream of the ATG start codon of each open reading frame. The consensus promoters, -10 (GATTAT, TATATC) and -35 sequences (TGCACA, TTTATA), were identified upstream of two open reading frames encoding SpvR and SpvC (Figs 4 and 5).

The DNA sequences and deduced amino acid sequences of the $s p v$ region of $S$. enteritidis were compared with the corresponding genes and proteins of the $S$. typhimurium, $S$. dublin and $S$. choleraesuis plasmids reported previously (Norel et al., 1989a, b, c; Pullinger et al., 1989; Taira \& Rhen, 1989a, b, 1990; Gulig \& Chiodo, 1990; Matsui et al., 1990a, b, 1993; Krause et al., 1991; Caldwell \& Gulig, 1991; Gulig et al., 1992). There were no significant differences in the nucleotide sequences in the coding regions between the $s p v$ region from $S$. enteritidis and the other three serotypes. In the $\operatorname{spv} \mathrm{R}$ and $\operatorname{spv} A$ regions, substitutions of 2 and 1-3 nucleotides were observed, resulting in 2 and $1-3$ amino acid alterations, respectively. In the $s p v B$ and $s p v C$ regions, substitutions of 3-9 and $0-3$ nucleotides were observed, respectively, except for the sequences described by Norel et al. (1989a, b), resulting in 1-4 and 0-3 amino acid alterations, respectively. As shown in Table 2, the identity of each deduced amino acid sequence in the $s p v$ region of $S$. enteritidis to the corresponding sequences in the $s p v$ region of other plasmids exceeded $98 \%$ except for the results reported by Norel et al. (1989a, b). As cited by Taira \& Rhen (1989a) and Gulig et al. (1992), some substitutions and deletions 
Table 2. Comparison of deduced amino acid sequences of Spv proteins encoded in the spv regions of the $S$. enteritidis plasmid with those of other Salmonella virulence plasmids

\begin{tabular}{|c|c|c|c|c|c|}
\hline \multirow[t]{2}{*}{ Serotype } & \multicolumn{4}{|c|}{ Percentage identity to: } & \multirow[t]{2}{*}{ Reference(s) } \\
\hline & SpvR & SpvA & SpvB & SpvC & \\
\hline S. choleraesuis & $99 \cdot 3$ & $99 \cdot 6$ & $99 \cdot 3$ & $98 \cdot 9$ & $\begin{array}{l}\text { Matsui et al. } \\
\text { (1990a, b, 1993) }\end{array}$ \\
\hline S. dublin & $99 \cdot 3$ & $99 \cdot 2$ & $99 \cdot 5$ & $100 \cdot 0$ & $\begin{array}{l}\text { Krause et al. } \\
\text { (1991) }\end{array}$ \\
\hline \multirow[t]{4}{*}{ S. typhimurium } & $99 \cdot 3$ & $99 \cdot 2$ & $99 \cdot 3$ & $100 \cdot 0$ & $\begin{array}{l}\text { Taira \& Rhen } \\
(1989 a, b, 1990)\end{array}$ \\
\hline & $99 \cdot 3$ & $98 \cdot 8$ & $94 \cdot 4$ & $87 \cdot 1$ & $\begin{array}{l}\text { Norel et al. } \\
\quad(1989 \text { a, b, c) }\end{array}$ \\
\hline & $99 \cdot 3$ & $99 \cdot 2$ & $99 \cdot 8$ & $99 \cdot 6$ & $\begin{array}{l}\text { Caldwell \& } \\
\text { Gulig (1991), } \\
\text { Gulig \& } \\
\text { Chiodo (1990), } \\
\text { Gulig et al. } \\
\text { (1992) }\end{array}$ \\
\hline & $99 \cdot 3$ & ND* & ND & ND & $\begin{array}{l}\text { Pullinger et al. } \\
(1989)\end{array}$ \\
\hline
\end{tabular}

ND, Not determined.

* Unpublished.

of nucleotides exist between the $s p v B$ and $s p v C$ regions of $S$. enteritidis and the corresponding regions reported by Norel et al. (1989a, b), respectively, resulting in the relatively low percentages of identity (Table 2 ).

\section{DNA sequence analysis of the $\operatorname{Tn} 1$ insertion}

To identify the precise location of the $\operatorname{Tn} 1$ insertion site of strain TA19, the DNA sequences flanking the Tn1 insertion of pNEG19 were determined. The insertion site was located at base 3647 of the $4.1 \mathrm{~kb}$ EcoRI-EcoRI fragment within the coding sequence of SpvC (Fig. 5).

\section{DISCUSSION}

Several authors have reported the presence of a homologous region in the $S$. enteritidis plasmid to the virulence region of the S. typhimurium and S. dublin plasmids based on DNA hybridization studies (Popoff et al., 1984; Beninger $e t$ al., 1988; Williamson $e t$ al., 1988a; Korpela $e t$ al., 1989; Poppe et al., 1989; Woodward et al., 1989; Roudier et al., 1990; Jones \& Osborne, 1991). Recently, heteroduplex analysis of the virulence plasmids of several serotypes has shown that the $S$. typhimurium, $S$. choleraesuis and $S$. enteritidis plasmids were very similar (Montenegro et al., 1991). Moreover, Williamson et al. (1988a) demonstrated the avirulence in mice of $S$. enteritidis mutants in which the transposon-containing sequences from the virulence region of the plasmid of S. typhimurium M242 or
S. dublin M51 were transduced into the plasmid. Therefore, it has been suggested that the homologous region in the $S$. enteritidis plasmid presumably contributed to the virulence. However, the precise location of the homologous region on the restriction map of the $S$. enteritidis plasmid has not been defined. In the present study, we constructed the restriction enzyme map of the $S$. enteritidis plasmid pNL2001 (Fig. 1a) and showed, based on Southern blotting analysis, that a $6.4 \mathrm{~kb}$ Sall-EcoRI region of the $S$. enteritidis plasmid was homologous to the $6.4 \mathrm{~kb} S a l \mathrm{I}-E c o \mathrm{RI} s p v$ region of the $S$. choleraesuis plasmid (Fig. 2). One mutant, TA19, in which $\operatorname{Tn} 1$ had been inserted within the homologous region, showed reduced mouse lethality (Table 1). Although we could not obtain any other mutants in which $\mathrm{Tn} 1$ had been inserted within the homologous region, S. enteritidis transductants described by Williamson et al. (1988a) were not virulent in mice, and the transposon insertions were located within the $2.3 \mathrm{~kb} S a l-E c o \mathrm{RI}$ and $4.1 \mathrm{~kb} E c o \mathrm{RI}-E_{c o} \mathrm{RI}$ fragments (Baird et al., 1985). On the basis of these results, it was suggested that the homologous region in the S. enteritidis plasmid pNL2001 was responsible for virulence in mice. This homologous region was mapped on pNL2001 as the $s p v$ region of S. enteritidis plasmid (Fig. 1a).

Four proteins were detected from the $6.4 \mathrm{~kb} s p v$ region of pNL2001 by Western blotting analysis using individual Spv protein antisera (Fig. 3), and at least four open reading frames corresponding to the individual proteins were identified within the DNA sequence of this region (Figs 4 and 5). We designated these $S$. enteritidis genes $s p v R, s p v A, s p v B$ and $s p v C$, encoding $32,32,70$ and $29 \mathrm{kDa}$ proteins, respectively. The $s p v$ genes were oriented in the same direction as shown in Fig. 1(a), and corresponded to the sequences of the $s p v$ genes recently identified in the S. typhimurium, $S$. dublin and $S$. choleraesuis virulence plasmids. Comparison of the DNA sequences and deduced amino acid sequences of our $s p v$ region with those of the other serotypes showed that the $s p v \mathrm{R}, \operatorname{spv} A$, $s p v B$ and $s p v C$ genes of $S$. enteritidis were nearly identical to the $s p v \mathrm{R}, s p v A, s p v B$ and $s p v C$ genes of the other three serotypes (Norel et al., 1989a, b, c; Pullinger et al., 1989; Taira \& Rhen, 1989a, b, 1990; Gulig \& Chiodo, 1990; Matsui et al., 1990a, b, 1993; Krause et al., 1991; Caldwell \& Gulig, 1991; Gulig et al., 1992), respectively (Table 2). Therefore, it was confirmed that the virulence plasmids of non-typhoidal Salmonellae, including $S$. enteritidis, share the highly conserved region responsible for the virulence, although the virulence plasmids carried by different serotypes differed in their size and restriction digest pattern (Popoff et al., 1984). However, in this study, we could not define the region downstream of the $s p \nu C$ gene in $S$. enteritidis, where the $s p v D$ and orfE genes were identified in S. typhimurium and S. dublin (Krause et al., 1991; Gulig et al., 1992, 1993). Considering the almost complete identity of our $s p v \mathrm{R} A B C$ genes to those of the other three serotypes and the extensive region of homology among the Salmonella virulence plasmids (Montenegro et al., 1991), it is likely that the $s p v D$ and orf $E$ genes are also encoded in $S$. enteritidis, and it would be unsurprising if they are nearly identical to those of the 
other serotypes. Identification of these genes in $S$. enteritidis will therefore require further investigation.

Woodward et al. (1989) reported that the virulence plasmids of S. typhimurium, $S$. dublin and $S$. enteritidis share the approximately $10 \mathrm{MDa}$ homologous region containing the virulence region, and Lax et al. (1990) demonstrated the similarity of the two regions, approximately $22 \mathrm{~kb}$ encompassing the virulence region and $8 \mathrm{~kb}$ outside it, between the $S$. dublin and $S$. typhimurium plasmids. The heteroduplex analysis of Salmonella virulence plasmids by Montenegro et al. (1991) also showed that the virulence plasmids of $S$. typhimurium, $S$. dublin, $S$. choleraesuis and $S$. enteritidis share large regions of homology. In fact, the restriction enzyme map of the $S$. enteritidis plasmid pNL2001 (Fig. 1a) revealed that the restriction sites of the enzymes on the pNL2001 plasmid, especially on the region encompassing the $s p v$ region, were very similar to those of the S. choleraesuis plasmid pKDSC50 (Kawahara et al., 1990). In a recent study, Selander et al. (1992) suggested the evolutionary derivation of $S$. dublin from an S. enteritidis-like ancestor based on the similarities of the multilocus enzyme genotype and nucleotide sequence of fiC gene between $S$. dublin and $S$. enteritidis. It is thus possible that the Salmonella virulence plasmids have conserved a uniform region including the virulence region and have been constructed, serotype-specifically, by the addition or deletion of the non-homologous region through an evolutionary process, as previously suggested by Williamson $e$ al. (1988a).

The $29 \mathrm{kDa}$ protein was detected from the subclones JM109/pNE192 and JM109/pNE182, which carried the Bam HI-EcoRI fragment in opposite orientations against the lac $Z$ promoter of the vector plasmid, suggesting the presence of the promoter for the $s p v C$ gene within the fragment. Based on the DNA sequence analysis, -10 and -35 regions for the consensus promoter were located 23 and 45 bases upstream from the start codon for the $s p \nu C$ gene of S. enteritidis, respectively. Gulig \& Curtiss (1988) and Gulig \& Chiodo (1990) suggested the presence of the promoter, which was located approximately 300 bases upstream from the start codon for the $s p v C$ gene of $S$. typhimurium plasmid. Thus, there is a discrepancy in the location of the consensus promoter sequence between the results reported by Gulig \& Chiodo (1990) and ours, although both promoter sequences were detected within each Bam HI-EcoRI fragment. Most recently, complementation experiments for virulence in mice and for $\beta$ galactosidase activity expressed by the $s p v-l a c Z$ fusions in E. coli and S. typhimurium have revealed that the $s p v C$ gene was transcribed from a promoter located in the $0.4 \mathrm{~kb}$ BamHI-StuI fragment, downstream of $s p v B$ (Coynault $e t$ al., 1992). The identification of the derivatives deleted from the BamHI site of the BamHI-EcoRI fragment will be necessary to determine the precise location of the promoter for the $s p v C$ gene.

The function of the products from individual genes within the $s p v$ region of $S$. enteritidis remains largely unknown. In the present study, we showed that the strain TA19 displayed a reduced mouse lethality, and that $\operatorname{Tn} 1$ was located within the $\operatorname{spv} C$ gene encoding the $29 \mathrm{kDa}$ protein. Complementation examinations confirmed that the $\operatorname{spv} C$ region of $S$. typhimurium encoding a $28 \mathrm{kDa}$ protein was essential for the expression of virulence in mice (Gulig \& Chiodo, 1990; Coynault et al., 1992). However, a non-polar insertion mutation of $s p v C$ of $S$. dublin retained a partial virulence phenotype for mice, suggesting the presence of the accessory virulence function of the $s p v C$ gene (Roudier $e t$ al., 1992). On the basis of these results and ours, it is suggested that the $29 \mathrm{kDa}$ protein encoded by the $s p v C$ gene of $S$. enteritidis may contribute to mouse lethality. To confirm the role of our SpvC protein in virulence, it will be necessary to examine the complementation by the $s p v C$ gene of $S$. enteritidis. Recent studies have demonstrated that the $s p v \mathrm{R}$ gene products of S. typhimurium, $S$. dublin and S. choleraesuis positively regulated the expression of downstream $s p v$ genes through the $\operatorname{spv} A$ promoter (Caldwell \& Gulig, 1991; Fang et al., 1991; Krause et al., 1992; Matsui et al., 1991, 1993; Taira et al., 1991; Coynault et al., 1992). The contribution of the $s p v \mathrm{R}$ and $s p v D$ genes to virulence in mice was also confirmed by recent complementation studies (Gulig et al., 1992; Coynault et al., 1992), whilst the definitive roles of $s p v A$ and $s p v B$ genes has been controversial (Gulig et al., 1993). It is assumed that since the sequences of our $s p v$ genes are almost identical with those of the $s p v$ genes previously reported, our $s p v$ genes presumably exert a similar function to that of the $s p v$ genes in the other three serotypes.

Although it remains to be determined how the virulence gene products contribute to pathogenesis, recent investigations have demonstrated that the $s p v$ genes were selectively expressed during the stationary phase of culture or under starvation conditions (Fang et al., 1991; Krause et al., 1992; Coynault et al., 1992) and were regulated by a chromosomal gene kat $F$ which encodes an alternative $\sigma$ factor of RNA polymerase (Fang et al., 1992; Norel et al., 1992). Rhen et al. (1989) reported that Tn5 insertion within the $s p v B$ region induced a low viability of $S$. typhimurium in murine liver macrophages, indicating that the spvB gene was necessary for intracellular growth of bacteria. In contrast, Riikonen et al. (1992) reported that the $s p v$ genes of the Salmonella virulence plasmids did not contribute to the survival or growth of Salmonellae in murine macrophages cultured in vitro. In the most recent study by Gulig \& Doyle (1993), it was indicated that the virulence plasmid of $S$. typhimurium contributed to virulence in mice by the increase of growth rate of the bacteria presumably within mouse cells, and not through the induction of resistance to killing by the host or the increase of the mobility of the bacteria between tissues. Therefore, the $s p v$ gene products are likely to be expressed under regulation of a chromosomal gene kat $F$ in mouse cells where the nutrient conditions are limited. Thereafter the growth rate of bacteria may increase, resulting in lethality for mice. The higher recovery rates of bacteria from the deeper tissues in mice infected with the parent $S$. enteritidis strain compared with the plasmid-cured derivative described in our previous study (Suzuki et al., 1992) and the reduced mouse lethality of the $s p v C$ insertion 
mutant in the present study may be ascribed to this mechanism.

\section{ACKNOWLEDGEMENTS}

We thank Mr Y. Saitoh, The Kitasato Institute, for his excellent technical assistance. We also thank Professor K. Ogimoto, Tohoku University, Dr S. Y. Murayama, Teikyo University School of Medicine, Dr N. Hirayama, Bureau of Livestock Industry, Ministry of Agriculture, Forestry and Fisheries, Dr T. Sawada, Nippon Veterinary and Animal Science University, and Dr T. Takahashi, National Veterinary Assay Laboratory, for their encouragement and support throughout this study.

\section{REFERENCES}

Baird, G. D., Manning, E. J. \& Jones, P. W. (1985). Evidence for related virulence sequences in plasmids of Salmonella dublin and Salmonella typhimurium. J Gen Microbiol 131, 1815-1823.

Beninger, P. R., Chikami, G., Tanabe, K., Roudier, C., Fierer, J. \& Guiney, D. G. (1988). Physical and genetic mapping of the Salmonella dublin virulence plasmid pSDL2. J Clin Invest 81, 1341-1347.

Bolivar, F. \& Backman, K. (1979). Plasmids of Escherichia coli as cloning vectors. Methods Enzymol 68, 245-267.

Caldwell, A. L. \& Gulig, P. A. (1991). The Salmonella typhimurium virulence plasmid encodes a positive regulator of a plasmidencoded virulence gene. J Bacteriol 173, 7176-7185.

Chang, A. C. \& Cohen, S. N. (1978). Construction and characterization of amplifiable multicopy DNA cloning vehicles derived from the P15A cryptic miniplasmid. J Bacteriol 134, 1141-1156.

Cohen, S. N., Chang, A. C. Y. \& Hsu, L. (1972). Nonchromosomal antibiotic resistance in bacteria: genetic transformation of Escherichia coli by R-factor DNA. Proc Natl Acad Sci USA 69, 2110-2114.

Coynault, C., Robbe-Saule, V., Popoff, M. Y. \& Norel, F. (1992). Growth phase and SpvR regulation of transcription of Salmonella typhimurium spv $A B C$ virulence genes. Microb Pathog 13, 133-143.

Fang, F. C., Krause, M., Roudier, C., Fierer, J. \& Guiney, D. G. (1991). Growth regulation of a Salmonella plasmid gene essential for virulence. J Bacteriol 173, 6783-6789.

Fang, F. C., Libby, S. J., Buchmeier, N. A., Loewen, P. C., Switala, J., Harwood, J. \& Guiney, D. G. (1992). The alternative $\sigma$ factor KatF (RpoS) regulates Salmonella virulence. Proc Natl Acad Sci US A 89, 11978-11982.

Gulig, P. A. (1990). Virulence plasmids of Salmonella typhimurium and other salmonellae. Microb Pathog 8, 3-11.

Gulig, P. A. \& Chiodo, V. A. (1990). Genetic and DNA sequence analysis of the Salmonella typhimurium virulence plasmid gene encoding the 28000-molecular-weight protein. Infect Immun 58, 2651-2658.

Gulig, P. A. \& Curtiss, R., III (1987). Plasmid-associated virulence of Salmonella typhimurium. Infect Immun 55, 2891-2901.

Gulig, P. A. \& Curtiss, R., III (1988). Cloning and transposon insertion mutagenesis of virulence genes of the 100-kilobase plasmid of Salmonella typhimurium. Infect Immun 56, 3262-3271.

Gulig, P. A. \& Doyle, T. J. (1993). The Salmonella typhimurium virulence plasmid increases the growth rate of salmonellae in mice. Infect Immun 61, 504-511.

Gulig, P. A., Caldwell, A. L. \& Chiodo, V. A. (1992). Identification, genetic analysis and DNA sequence of a $7 \cdot 8-\mathrm{kb}$ virulence region of the Salmonella typhimurium virulence plasmid. Mol Microbiol 6, 1395-1411.
Gulig, P. A., Danbara, H., Guiney, D. G., Lax, A. J., Norel, F. \& Rhen, M. (1993). Molecular analysis of $s p v$ virulence genes of the salmonella virulence plasmids. Mol Microbiol 7, 825-830.

Harayama, S., Tsuda, M. \& lino, T. (1980). High frequency mobilization of the chromosome of Escherichia coli by a mutant of plasmid RP4 temperature-sensitive for maintenance. Mol \& Gen Genet 180, 47-56.

Heffernan, E. J., Fierer, J., Chikami, G. \& Guiney, D. (1987). Natural history of oral Salmonella dublin infection in BALB/c mice: effect of an 80-kilobase-pair plasmid on virulence. J Infect Dis $\mathbf{1 5 5}$, 1254-1259.

Heffron, F., McCarthy, B. J., Ohtsubo, H. \& Ohtsubo, E. (1979). DNA sequence analysis of the transposon $\operatorname{Tn} 3:$ three genes and three sites involved in transposition of Tn3. Cell 18, 1153-1163.

Holmes, D. S. \& Quigley, M. (1981). The rapid boiling method for the preparation of bacterial plasmids. Anal Biochem 114, 193-197.

Hovi, M., Sukupolvi, S., Edwards, M. F. \& Rhen, M. (1988). Plasmid-associated virulence of Salmonella enteritidis. Microb Pathog 4, 385-391.

Jones, C. S. \& Osborne, D. J. (1991). Identification of contemporary plasmid virulence genes in ancestral isolates of Salmonella enteritidis and Salmonella typhimurium. FEMS Microbiol Lett 80, 7-12.

Kado, C. I. \& Liu, S.-T. (1981). Rapid procedure for detection and isolation of large and small plasmids. J Bacteriol 145, 1365-1373.

Kärber, G. (1931). Beitrag zur kollektiven Behandlung pharmakologischer Reihenversuche. Arch Exp Pathol Pharmakol 162, 480.

Kawahara, K., Haraguchi, Y., Tsuchimoto, M., Terakado, N. \& Danbara, H. (1988). Evidence of correlation between 50-kilobase plasmid of Salmonella choleraesuis and its virulence. Microb Pathog 4, 155-163.

Kawahara, K., Tsuchimoto, M., Sudo, K., Terakado, N. \& Danbara, H. (1990). Identification and mapping of $m b a$ regions of the Salmonella choleraesuis virulence plasmid pKDSC50 responsible for mouse bacteremia. Microb Pathog 8, 13-21.

Korpela, K., Ranki, M., Sukupolvi, S., Mäkelä, P. H. \& Rhen, M. (1989). Occurrence of Salmonella typhimurium virulence plasmidspecific sequences in different serovars of Salmonella. FEMS Microbiol Lett 58, 49-54.

Krause, M., Roudier, C., Fierer, J., Harwood, J. \& Guiney, D. (1991). Molecular analysis of the virulence locus of the Salmonella dublin plasmid pSDL2. Mol Microbiol 5, 307-316.

Krause, M., Fang, F. C. \& Guiney, D. G. (1992). Regulation of plasmid virulence gene expression in Salmonella dublin involves an unusual operon structure. J Bacteriol 174, 4482-4489.

Kushner, S. R. (1978). An improved method for transformation of Escherichia coli with ColE1-derived plasmids. In Genetic Engineering, pp. 17-23. Edited by H. B. Boyer \& S. Nicosia. Amsterdam: Elsevier.

Laemmli, U. K. (1970). Cleavage of structural proteins during the assembly of the head of bacteriophage T4. Nature 227, 680-685.

Lax, A. J., Pullinger, G. D., Baird, G. D. \& Williamson, C. M. (1990). The virulence plasmid of Salmonella dublin: detailed restriction map and analysis by transposon mutagenesis. J. Gen Microbiol 136, 1117-1123.

Lennox, E. S. (1955). Transduction of linked genetic characters of the host by bacteriophage P1. Virology 1, 190-206.

Matsui, H., Kawahara, K., Terakado, N. \& Danbara, H. (1990a). Nucleotide sequence of a gene encoding a $29 \mathrm{kDa}$ polypeptide in $m b a$ region of the virulence plasmid, pKDSC50, of Salmonella choleraesuis. Nucleic Acids Res 18, 1055. 
Matsui, H., Kawahara, K., Terakado, N. \& Danbara, H. (1990b). Nucleotide sequences of genes encoding $32 \mathrm{kDa}$ and $70 \mathrm{kDa}$ polypeptides in mba region of the virulence plasmid, pKDSC50, of Salmonella choleraesuis. Nucleic Acids Res 18, 2181-2182.

Matsui, H., Abe, A., Kawahara, K., Terakado, N. \& Danbara, H. (1991). Positive regulator for the expression of Mba protein of the virulence plasmid, pKDSC50, of Salmonella choleraesuis. Microb Pathog 10, 459-464.

Matsui, H., Abe, A., Suzuki, S., Kijima, M., Tamura, Y., Nakamura, M., Kawahara, K. \& Danbara, H. (1993). Molecular mechanism of the regulation of expression of plasmid-encoded mouse bacteremia (mba) genes in Salmonella serovar Choleraesuis. Mol \& Gen Genet 236, 219-226.

Michiels, T., Popoff, M. Y., Durviaux, S., Coynault, C. \& Cornelis, G. (1987). A new method for the physical and genetic mapping of large plasmids: application to the localisation of the virulence determinants on the $90 \mathrm{~kb}$ plasmid of Salmonella typhimurium. Microb Pathog 3, 109-116.

Montenegro, M. A., Morelli, G. \& Helmuth, R. (1991). Heteroduplex analysis of Salmonella virulence plasmids and their prevalence in isolates of defined sources. Microb Pathog 11, 391-397.

Nakamura, M., Sato, S., Ohya, T., Suzuki, S. \& Ikeda, S. (1985). Possible relationship of a 36-Megadalton Salmonella enteritidis plasmid to virulence in mice. Infect Immun 47, 831-833.

Norel, F., Pisano, M. R., Nicoli, J. \& Popoff, M. Y. (1989a). Nucleotide sequence of the plasmid-borne virulence gene $m k f A$ encoding a $28 \mathrm{kDa}$ polypeptide from Salmonella typhimurium. Res Microbiol 140, 263-265.

Norel, F., Pisano, M. R., Nicoli, J. \& Popoff, M. Y. (1989b). Nucleotide sequence of the plasmid-borne virulence gene $m k f B$ from Salmonella typhimurium. Res Microbiol 140, 455-457.

Norel, F., Pisano, M. R., Nicoli, J. \& Popoff, M. Y. (1989c). A plasmid-borne virulence region $(2 \cdot 8 \mathrm{~kb})$ from Salmonella typhimurium contains two open reading frames. Res Microbiol 140, 627-630.

Norel, F., Robbe-Saule, V., Popoff, M. Y. \& Coynault, C. (1992). The putative sigma factor $\mathrm{KatF}$ (RpoS) is required for the transcription of the Salmonella typhimurium virulence gene $s p v B$ in Escherichia coli. FEMS Microbiol Lett 99, 271-276.

Popoff, M. Y., Miras, I., Coynault, C. L., Lasselin, C. \& Pardon, P. (1984). Molecular relationships between virulence plasmids of Salmonella serotypes typhimurium and dublin and large plasmids of other Salmonella serotypes. Ann Microbiol (Paris) 135A, 389-398.

Poppe, C., Curtiss, R., III, Gulig, P. A. \& Gyles, C. L. (1989). Hybridization studies with a DNA probe derived from the virulence region of the $60 \mathrm{Mdal}$ plasmid of Salmonella typhimurium. Can J Vet Res 53, 378-384.

Pullinger, G. D., Baird, G. D., Williamson, C. M. \& Lax, A. J. (1989). Nucleotide sequence of a plasmid gene involved in the virulence of salmonellas. Nucleic Acids Res 17, 7983.

Rhen, M., Virtanen, M. \& Mäkelä, P. H. (1989). Localization by insertion mutagenesis of a virulence-associated region in the Salmonella typhimurium 96 kilobase pair virulence plasmid. Microb Pathog 6, 153-158.

Riikonen, P., Mäkelä, P. H., Saarilahti, H., Sukupolvi, S., Taira, S. \& Rhen, M. (1992). The virulence plasmid does not contribute to growth of Salmonella in cultured murine macrophages. Microb Patbog 13, 281-291.
Roudier, C., Krause, M., Fierer, J. \& Guiney, D. G. (1990). Correlation between the presence of sequences homologous to the vir region of Salmonella dublin plasmid pSDL2 and the virulence of twenty-two Salmonella serotypes in mice. Infect Immun 58, 1180-1185.

Roudier, C., Fierer, J. \& Guiney, D. G. (1992). Characterization of translation termination mutations in the spv operon of the Salmonella virulence plasmid pSDL2. J Bacteriol 174, 6418-6423.

Selander, R. K., Smith, N. H., Li, J., Beltran, P., Ferris, K. E., Kopecko, D. J. \& Rubin, F. A. (1992). Molecular evolutionary genetics of the cattle-adapted serovar Salmonella dublin. J Bacteriol 174, 3587-3592.

Short, J. M., Fernandez, J. M., Sorge, J. A. \& Huse, W. D. (1988). IZAP: a bacteriophage $\lambda$ expression vector with in vivo excision properties. Nucleic Acids Res 16, 7583.

Suzuki, S., Ohmae, K., Nakamura, M., Sato, S., Koeda, T., Ohishi, K. \& Muramatsu, M. (1989). Demonstration of the correlation of a 36-megadalton Salmonella serovar enteritidis plasmid to virulence in mice by reintroduction of the plasmid. Jpn J Vet Sci 51, 203-205.

Suzuki, S., Ohishi, K., Takahashi, T., Tamura, Y., Muramatsu, M., Nakamura, M. \& Sato, S. (1992). The role of 36 megadalton plasmid of Salmonella Enteritidis for the pathogenesis in mice. J Vet Med Sci 54, 845-850.

Taira, S. \& Rhen, M. (1989a). Identification and genetic analysis of $m k a A-a$ gene of the Salmonella typhimurium virulence plasmid necessary for intracellular growth. Microb Pathog 7, 165-173.

Taira, S. \& Rhen, M. (1989b). Molecular organization of genes constituting the virulence determinant on the Salmonella typhimurium 96 kilobase pair plasmid. FEBS Lett 257, 274-278.

Taira, S. \& Rhen, M. (1990). Nucleotide sequence of $m k a D$, a virulence-associated gene of Salmonella typhimurium containing variable and constant regions. Gene 93, 147-150.

Taira, S., Riikonen, P., Saarilahti, H., Sukupolvi, S. \& Rhen, M. (1991). The mkaC virulence gene of the Salmonella serovar Typhimurium $96 \mathrm{~kb}$ plasmid encodes a transcriptional activator. Mol \& Gen Genet 228, 381-384.

Takeshita, S., Sato, M., Toba, M., Masahashi, W. \& HashimotoGotoh, T. (1987). High-copy-number and low-copy-number plasmid vectors for lac $Z \alpha$-complementation and chloramphenicolor kanamycin-resistance selection. Gene 61, 63-74.

Viera, J. \& Messing, J. (1987). Production of single-strand plasmid DNA. Metbods Enzymol 153, 3-11.

Williamson, C. M., Baird, G. D. \& Manning, E. J. (1988a). A common virulence region on plasmids from eleven serotypes of Salmonella. J Gen Microbiol 134, 975-982.

Williamson, C. M., Pullinger, G. D. \& Lax, A. J. (1988b). Identification of an essential virulence region on Salmonella plasmids. Microb Pathog 5, 469-473.

Woodward, M. J., McLaren, I. \& Wray, C. (1989). Distribution of virulence plasmids within Salmonellae. $J$ Gen Microbiol 135, 503-511.

Yanisch-Perron, C., Viera, J. \& Messing, J. (1985). Improved M3 cloning vectors and host strains: nucleotide sequences of the M13mp18 and pUC19 vectors. Gene 33, 103-119.

Received 10 August 1993; revised 3 December 1993; accepted 13 December 1993. 